\title{
Directional Alignment of MG63 Cells on Polymer Surfaces Containing Point Microstructures
}

\author{
Christopher A. Mills, * Javier G. Fernandez, Elena Martinez, Miriam Funes, \\ Elisabeth Engel, Abdelhamid Errachid, Josep Planell, and Josep Samitier
}

\begin{abstract}
M G63 cells cultured on regular arrays of point microstructures (posts and holes) are shown to preferentially align at certain angles to the pattern of the structures, at $0^{\circ}, 30^{\circ}$, and $45^{\circ}$ in particular. The effect is found to be more pronounced for post rather than hole structures (although no significant difference is found for the angles the cells make to the holes or posts) and is thought to be due to the fact that the cells use the posts as anchorage points to hold themselves to the surface. It is also shown that cells preferentially align with the structures depending on the dimensions of the structures and the distance between neighboring structures. This is important when designing structured surfaces for cellsurface interaction studies for materials to be used in, for example, drug delivery or tissue engineering.
\end{abstract}

\author{
Keywords: \\ - cell adhesion \\ - imprinting \\ - microstructures \\ - polymers \\ - surfaces
}

\section{Introduction}

Two-dimensional (2D) structured surfaces have been used to examine the effect of surface topology on the behavior and physical characteristics of cells. ${ }^{[1-12]}$ This has led to the discovery that micro- and nanotopology causes cells to elongate, ${ }^{[9]}$ align to the direction of the surface pattern, ${ }^{[9,13-14]}$ to rearrange the extracellular matrix in contact with the surface, ${ }^{[11,15]}$ and to internally re-organize cellular components. ${ }^{\left[{ }^{9,12}\right]}$ It is also possible that the topography can

[] C. A. Mills, J. G. Fernandez, E. Martinez, M. Funes, E. Engel, A. Errachid, J. Samitier

Laboratori de Recerca en Nanobioenginyeria

Parc Cientific de Barcelona

C/Josep Samitier 1-5, 08028 Barcelona (Spain)

Fax: (+34) 934-037-181

E-mail: cmills@pcb.ub.es

A. Errachid, J. Samitier

Dept. Electrónica

Universitat de Barcelona

C/Martí i Franquès 1, 08028 Barcelona (Spain)

E. Engel, J. Planell

Universitat Politécnica de Catalunya

Dpt. Ciència dels Materials i Enginyeria Metal.lúrgica, ETSEIB

Avda. Diagonal 647, 08028 Barcelona (Spain) 


\section{Results}

Figure 1 shows MG63 cells after three-day culture on a) nonstructured PMMA and b) PMMA structured with $4-\mu \mathrm{m}^{2}$ posts. Figure $1 \mathrm{c}$ replicates $\mathrm{b}$ but includes examples of the angles that the cells make to the structural pattern. The arrows in Figure 1c show the direction of the pattern horizontal and vertical to the image axis; all angles are measured from either the vertical or the horizontal axis in $\approx 5^{\circ}$ increments. Measurements were taken where it was possible to see individual cells, or parts of cells, in areas of nonaggre-
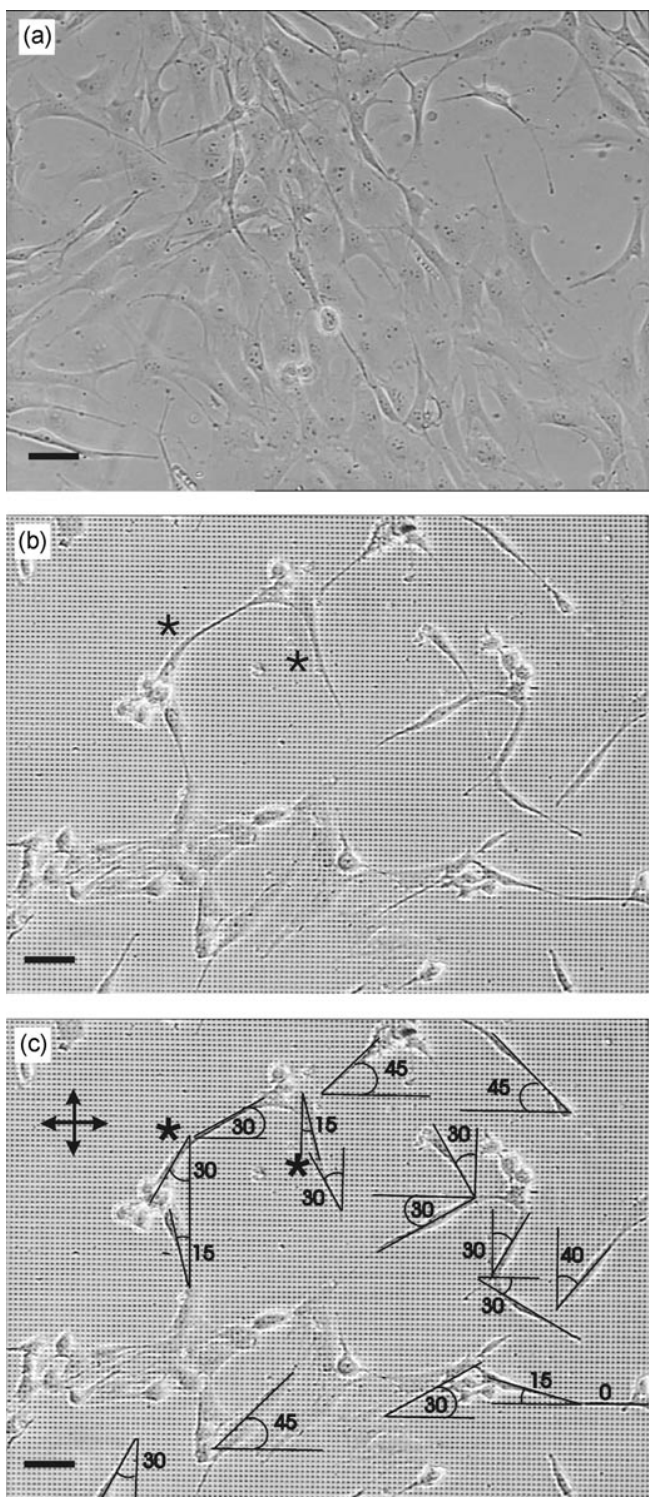

Figure 1. Optical image of cells cultured on a) nonstructured PMMA and b) PMMA structured with $4-\mu \mathrm{m}^{2}$ posts. The image shown in (c) is the same image as (b) and highlights the angles that the cells (or parts of the cell) make to the pattern of microstructures. The arrows in (c) show the direction of the pattern horizontal and vertical to the image axis, and angles are taken from either the vertical or the horizontal axis. The * in (b) and (c) indicates where an outgrowth of a single cell has changed its angle with respect to the pattern of the embossed structures (scale bar $=50 \mu \mathrm{m}$ ). gated cells. The * in b and $\mathrm{c}$ indicates where an outgrowth of a single cell has changed its angle with respect to the pattern of the embossed structures.

Figure 2 shows optical images of linear, elongated cells lying parallel to the surface pattern. The cells position themselves both between and on top of the surface structures. Figure 3 presents a variety of magnified optical images of single cells on an embossed but nonpatterned surface, and on the various patterned surfaces. Cells are shown in both linear and triaxial configurations. The length of some of the microspikes produced by the cells is apparent; for example, the microspike produced by the linear cell on the $25-\mu \mathrm{m}^{2}$ holes is $\approx 100 \mu \mathrm{m}$ long, almost twice the length of the cell itself. Figure 4 shows a fluorescence image of a cell on a surface containing $100-\mu \mathrm{m}^{2}$ posts. Vinculin in the focal adhesions of the cell to the surface are stained using paxilin and are colored green; the cell nucleus is stained with 4,6-diamidino-2-phenylindole (DAPI) and is colored blue. For ease of visualization the tops of the posts are colored red. Figure 5 gives the contact-angle measurements on the embossed, nonpatterned PMMA surface, and each of the arrays of embossed structures.

\section{Discussion}

Figure 1 shows that the cells on the nonstructured PMMA are confluent and randomly aligned and positioned. By comparison, fewer cells have grown on the structured PMMA surface and they are thinner and more elongated. The cells, or parts of the cells, are also aligned at specific angles to the pattern of the embossed structures. Figure 1c shows that these angles are consistent for all the cells when the cell is isolated. Changes in the direction of cell outgrowth are also seen to adhere to the same angles (evidenced by the indicated cell outgrowths).

Figures 6 and 7 show that, by examining a number of images in this way, a preference for certain angles appears. The total number of images and angles examined is given in Table $1 ; \approx 10$ angles were measured for each image studied.

To compare the data for the two types of structure (holes and posts) a two-tailed $t$-test was performed with the null hypothesis that there is no significant difference between the mean values of the angles made to the structural pattern. The mean angles made to the patterns were $21.93 \pm$ $16.16^{\circ}(n=722)$ for the posts and 23.29 $\pm 15.56^{\circ}(n=506)$ for the holes respectively. Experimentally $t_{\text {calc, } 1226}=1.47$, which is less than the tabulated $t_{0.05, \infty}=1.96 .{ }^{[21]}$ The null hypothesis is therefore accepted at the $95 \%$ confidence limit; the mean values of the angles made to the hole and post patterns are not significantly different and therefore the type of structure does not affect the average angle produced by the cells. This may be expected as the size of the structures is constant in each case but suggests that the cells are equally affected by the two different types of structure.

The large standard deviation does, however, suggest a degree of variation within the sample populations. A chisquared $\left(\chi^{2}\right)$ test was completed to determine whether there is a difference in the frequency of the angles measured in 

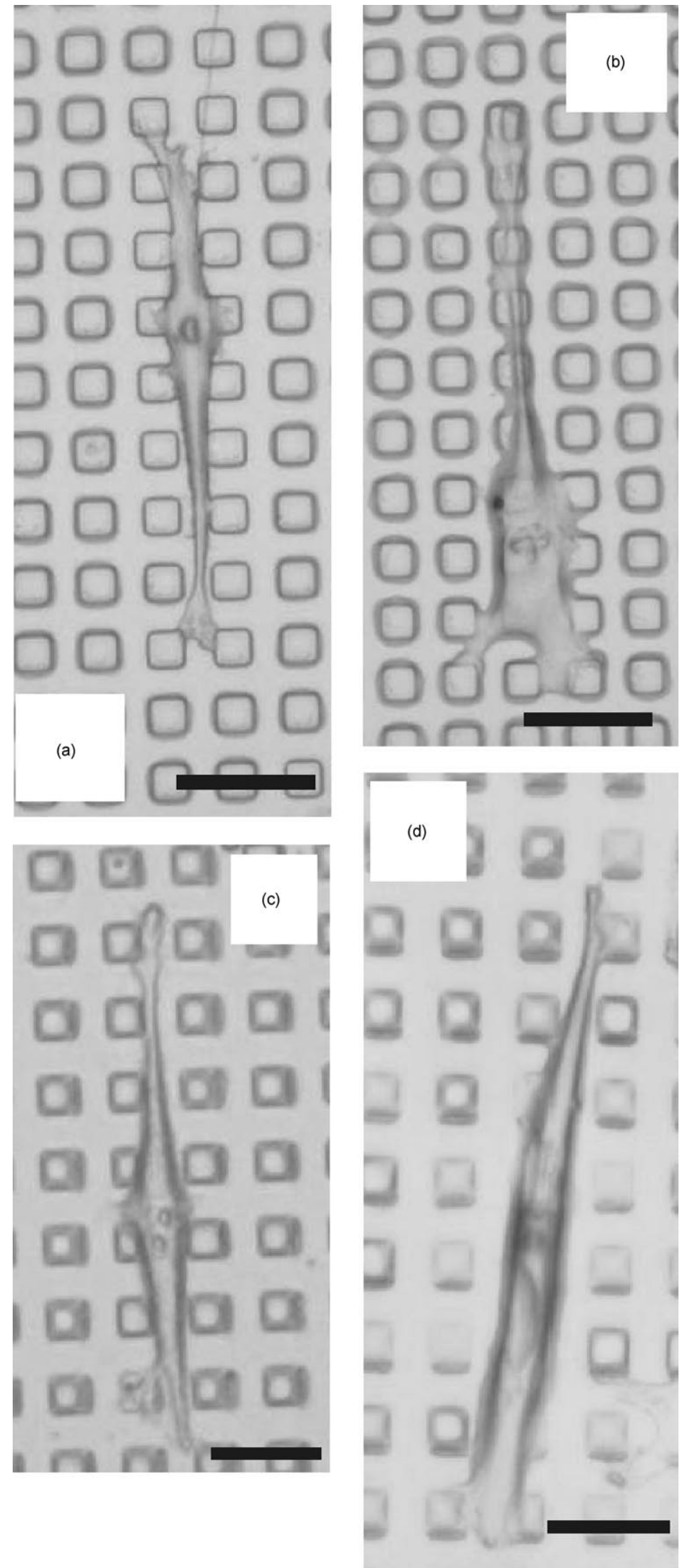

Figure 2. Examples of optical images of cells aligned with the pattern of $100-\mu \mathrm{m}^{2}$ structures on the surface of the PMMA. In each case, the cell aligns itself in a different position: a) between posts, b) on top of posts, c) between holes, and d) on top of holes (scale bar $=40 \mu \mathrm{m}$ ). each of the data sets. For this, the null hypothesis is that there is no difference in the frequency of the angles for each of the structures. For the posts, $\chi_{\text {calc }}^{2}=75.42, \quad 142.07$, and 100.18 for the 4,25 , and $100-\mu \mathrm{m}^{2}$ posts, respectively. Similarly for the holes, $\chi_{\text {calc }}^{2}=$ $39.25,43.06$, and 86.00 for the 4,25 , and $100-\mu \mathrm{m}^{2}$ holes, respectively. As $\chi_{9,0.05}^{2}=$ $16.92,{ }^{[21]}$ the null hypothesis is rejected; there is significant difference in the frequencies for all of the structural dimensions at the $95 \%$ confidence limit.

This can be seen in Figures 6 and 7 where the frequency of the 0,30 , and $45^{\circ}$ angles tends to be larger than the other angles measured. This preference could be explained in terms of the geometry of the patterned structures. Measuring the angle produced between consecutive posts, between post $(0,0)$ and $(0,1),(1,1),(2,1),(3,1)$, and so on, (Figure $8 \mathrm{a})$, reveals that the most common angles seen in Figures 6 and 7 are reproduced (Table 2). As the angle decreases, so the distance between posts in direct alignment increases (with the exception of $0^{\circ}$ ). The high frequency of the $0^{\circ}$, $30^{\circ}$, and $45^{\circ}$ angles in Figures 6 and 7 suggests that the cells prefer to align themselves to the structural pattern so that the distance between structures is minimized.

This argument is corroborated by modeling the cell on the structures. The centre of a theoretical rectangular cell is positioned at 16 positions around the unit cell of a regularly patterned surface (Figure $8 \mathrm{a}$ ). The theoretical cell is then rotated through $90^{\circ}$ (in $5^{\circ}$ steps) and the area of the cell that contacts the structures is calculated. The average area is then measured, to 


\section{full papers}
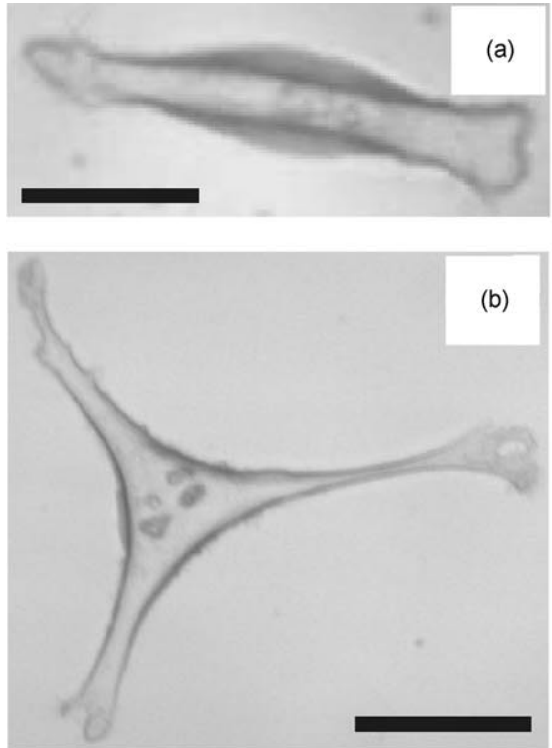

(c) गபบบบบบบบบ (c) 00000000000

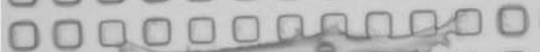

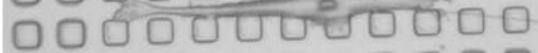
-20000000000
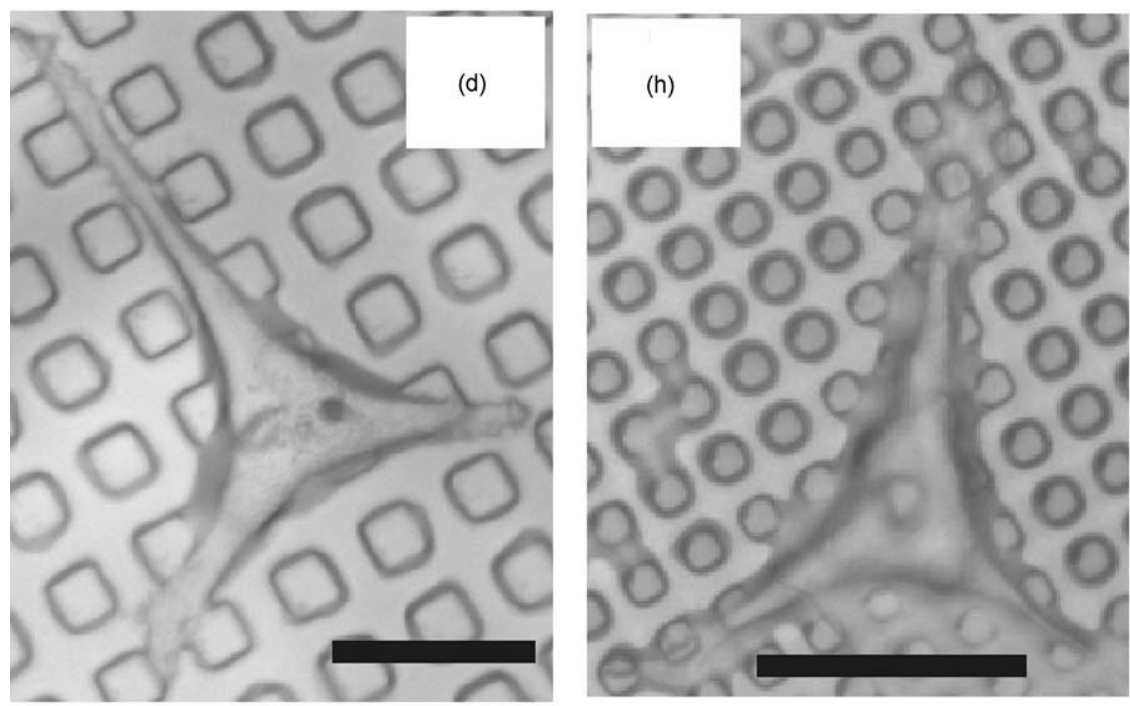

(g) 00000000000000 10000000000000000

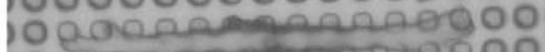

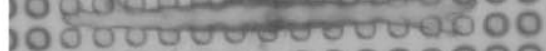
10000000000000000 r. h
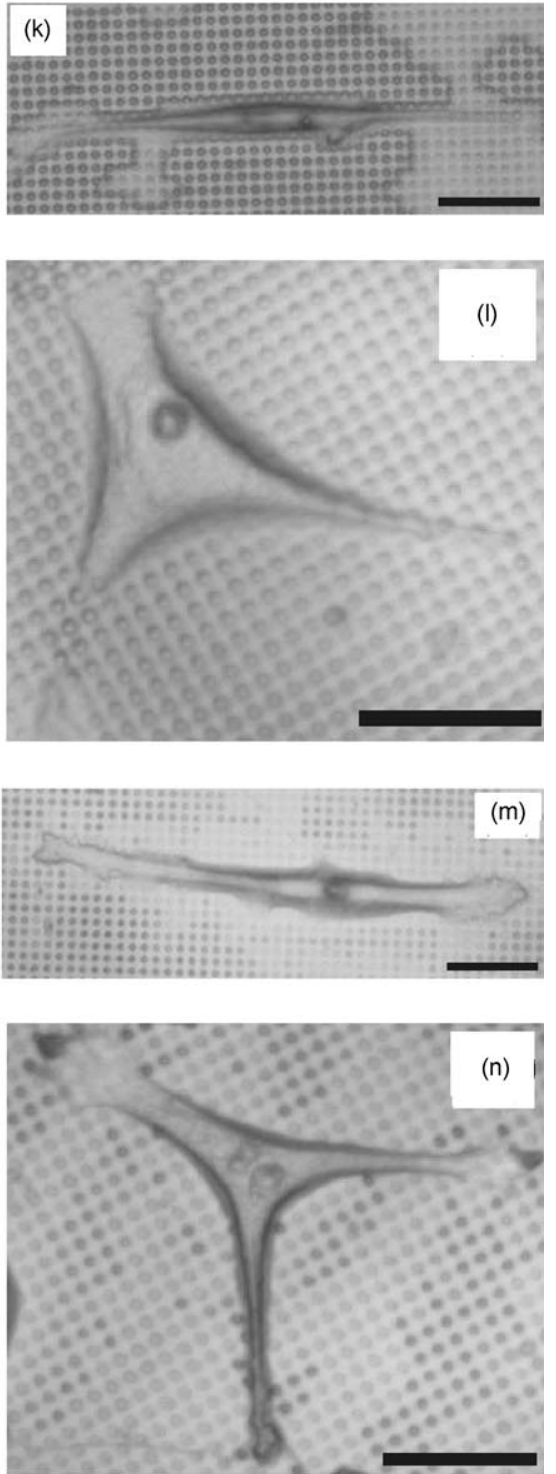

Figure 3. Optical images of single cells on the different types of structured PMMA surface with linear and triaxial shapes. a-b) Pristine PMMA (scale bar $=40 \mu \mathrm{m}$ ); c-d) $100-\mu \mathrm{m}^{2}$ posts, e-f) $100-\mu \mathrm{m}^{2}$ holes (scale bar $=40 \mu \mathrm{m}$ ); g-h) $25-\mu \mathrm{m}^{2}$ posts, $\mathrm{i}-\mathrm{j}$ ) $25-\mu \mathrm{m}^{2}$ holes $(\mathrm{scale} b a r=20 \mu \mathrm{m})$; $\mathrm{k}-\mathrm{l}) 4-\mu \mathrm{m}^{2}$ posts, $\left.\mathrm{m}-\mathrm{n}\right) 4-\mu \mathrm{m}^{2}$ holes (scale bar $=30 \mu \mathrm{m}$ ).

discover which angle causes the area of the cell sitting on the structures to be maximized. Figure $8 \mathrm{~b}-\mathrm{f}$ shows the results of this modeling when altering the width of the cell, $W$, compared to the width of the structures, $w$. The ratio of the widths decreases from b) $w=W$, c) $w=W / 2$, d) $w=W / 5$, e) $w=W / 10$, to f) $w=W / 50$. If a real cell is nominally $10 \mu \mathrm{m}$ 


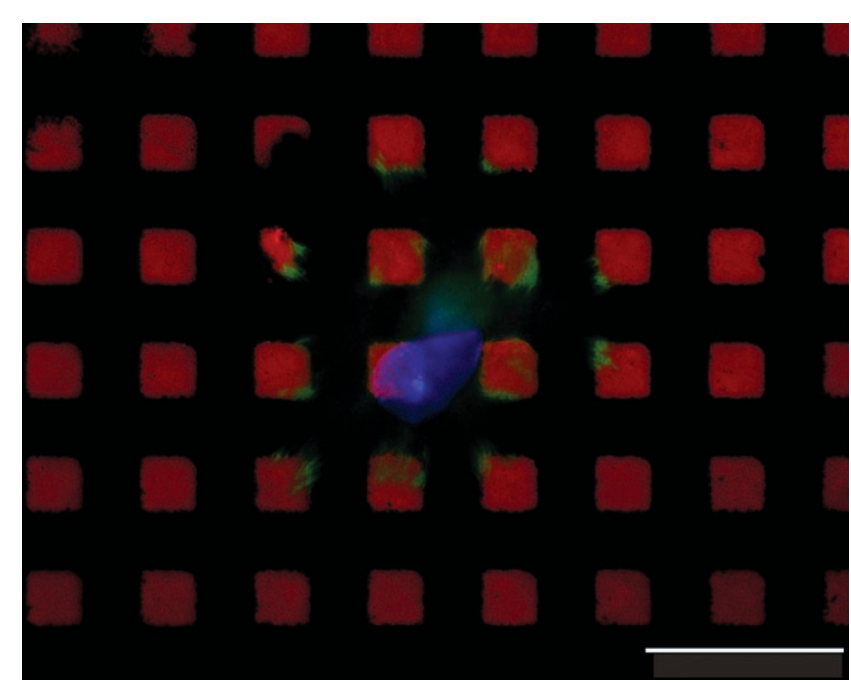

Figure 4. Fluorescence image of a cell on $100-\mu \mathrm{m}^{2}$ posts showing the vinculin in the focal adhesion points of the cell to the posts (green) and the cell nucleus (blue). The attachment points in this case are almost exclusively on the edges of the posts. To aid visualization, the tops of the posts have been colored red (scale bar $=35 \mu \mathrm{m}$ ).

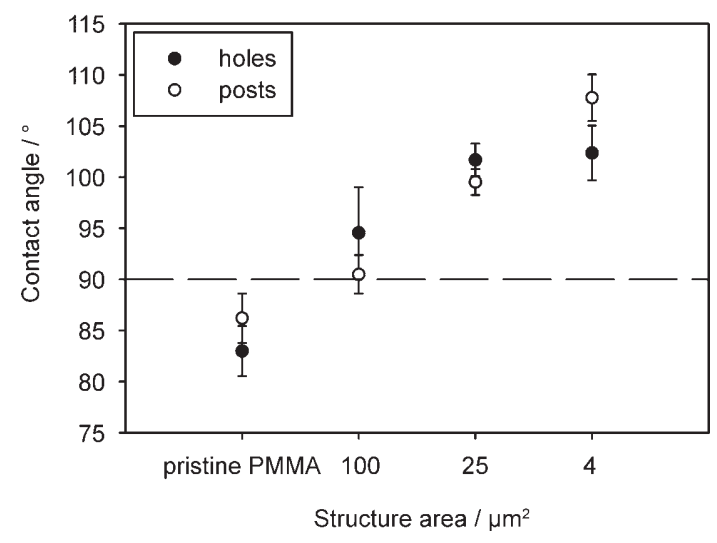

Figure 5. Advancing contact-angle measurements $\left(3 \mu \mathrm{L} \mathrm{H}_{2} \mathrm{O}\right)$ on PMMA surfaces containing holes and posts of different dimensions. Also given are the contact angles for the embossed, nonstructured PMMA in each case. The dashed line indicates the point of transition from hydrophilic to hydrophobic as the contact angle increases. The data is given as the mean of six measurements in each case.

in width, then the width of the structures taken from the model would be b) $10 \mu \mathrm{m}$, c) $5 \mu \mathrm{m}$, d) $2 \mu \mathrm{m}$, e) $1 \mu \mathrm{m}$, and f) $200 \mathrm{~nm}$. Figure $8 \mathrm{~g}$ combines the data from $\mathrm{b}-\mathrm{f}$ on one graph.

Figure 8 shows that when the width of the cell approximates to that of the structures, the area of the cell on the posts is maximized at certain angles, for example, when $w=$ $W, 30^{\circ}$ is dominant. As the structure width decreases, the area of the cell on the structures approaches $25 \%$, although certain angles still dominate to a lesser extent. Even when $w=W / 50$, there are dominant angles (e.g., $45^{\circ}$ and $20^{\circ}$ ). However, a real cell would probably interact with a surface containing point structures at these dimensions through subcellular interactions rather than through any bulk cellular alignment, for example, through integrin rearrangement. ${ }^{[22]}$

The predominance of the $30^{\circ}$ angle in the experimental results suggests that the majority of the cells have widths

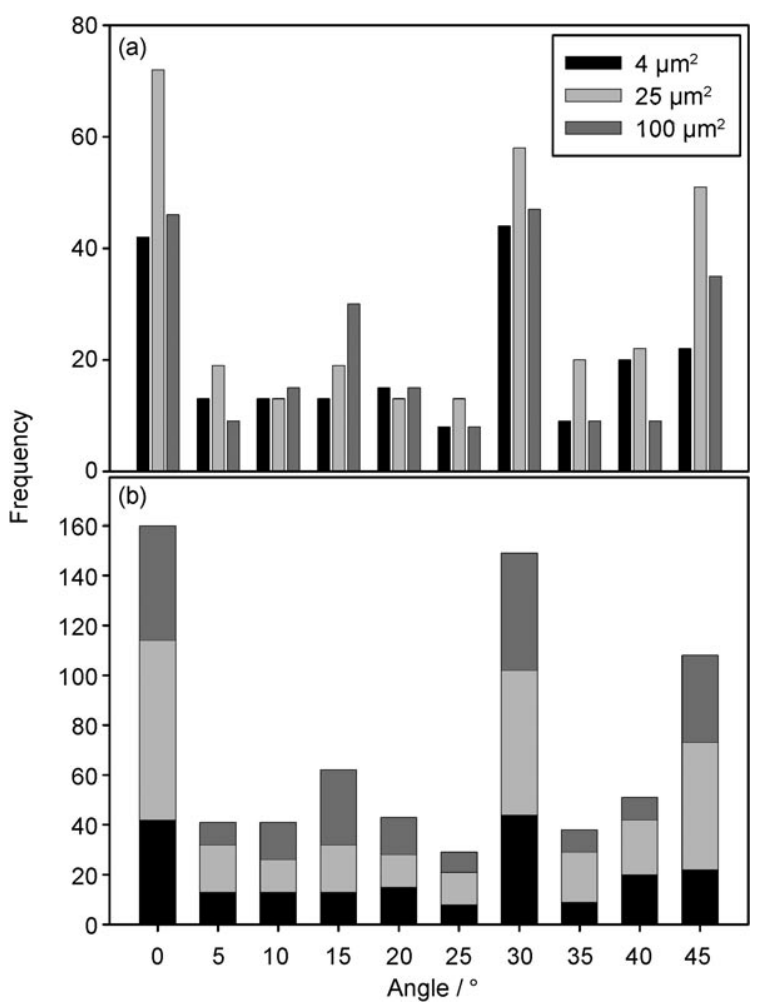

Figure 6. a) Grouped and b) cumulative frequency graphs of the angles the cells make to arrays of 4,25 , and $100-\mu \mathrm{m}^{2}$ posts that are $1 \mu \mathrm{m}$ tall. (Total number of images studied $=63$, total number of angles measured $=722$.)

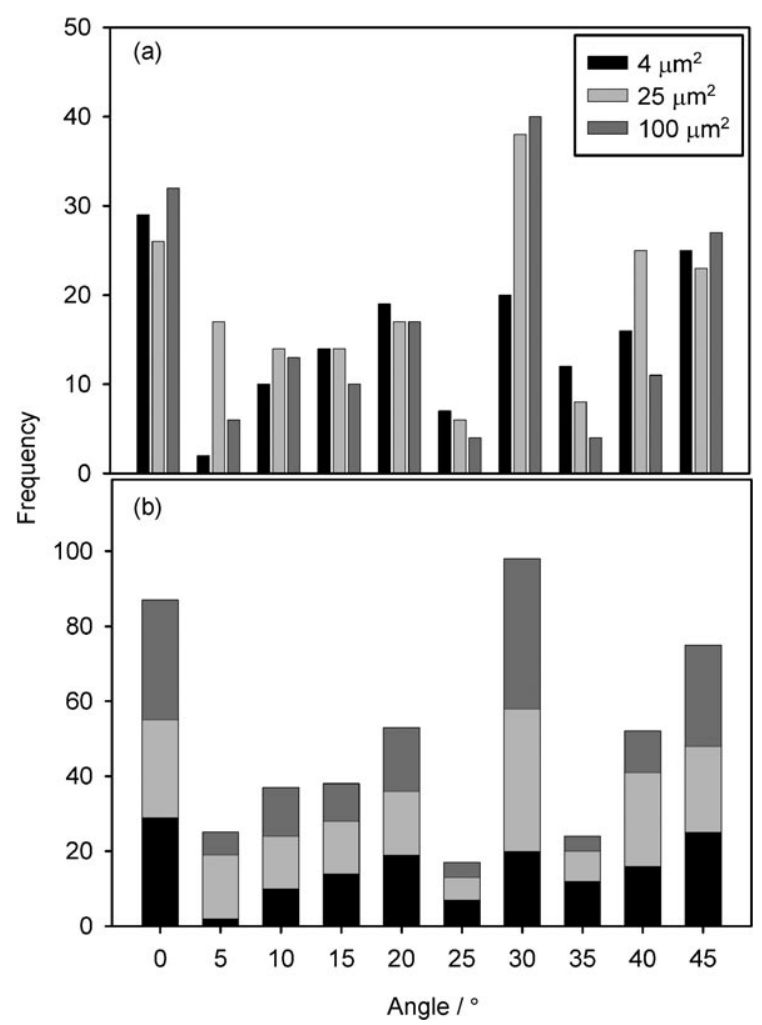

Figure 7. a) Grouped and b) cumulative frequency graphs of the angles the cells make to arrays of 4,25 , and $100-\mu \mathrm{m}^{2}$ holes that are $1 \mu \mathrm{m}$ deep. (Total number of images studied $=52$, total number of angles measured $=506$.) 
Table 1. Average number of angles measured per optical image.

\begin{tabular}{lcccc}
\hline & $4 \mu \mathrm{m}^{2}$ & $25 \mu \mathrm{m}^{2}$ & $100 \mu \mathrm{m}^{2}$ & Total \\
\hline Posts & & & & \\
Angles & 199 & 300 & 223 & 722 \\
Images & 20 & 21 & 22 & 63 \\
Angles/Image & 10 & 14 & 10 & 11 \\
Holes & 154 & 188 & 164 & 506 \\
Angles & 17 & 21 & 14 & 52 \\
Images & 9 & 9 & 12 & 10 \\
Angles/Image & & & & \\
\hline
\end{tabular}

(a)

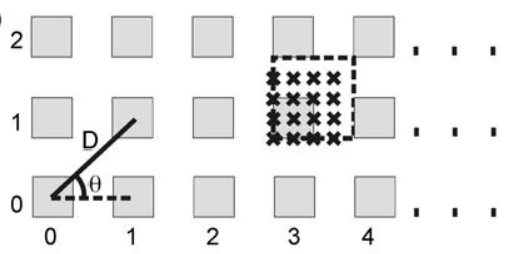

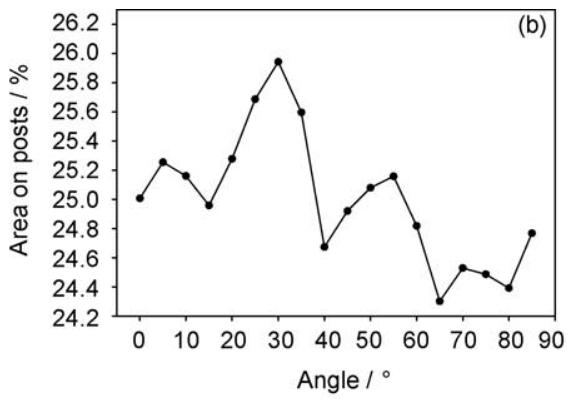
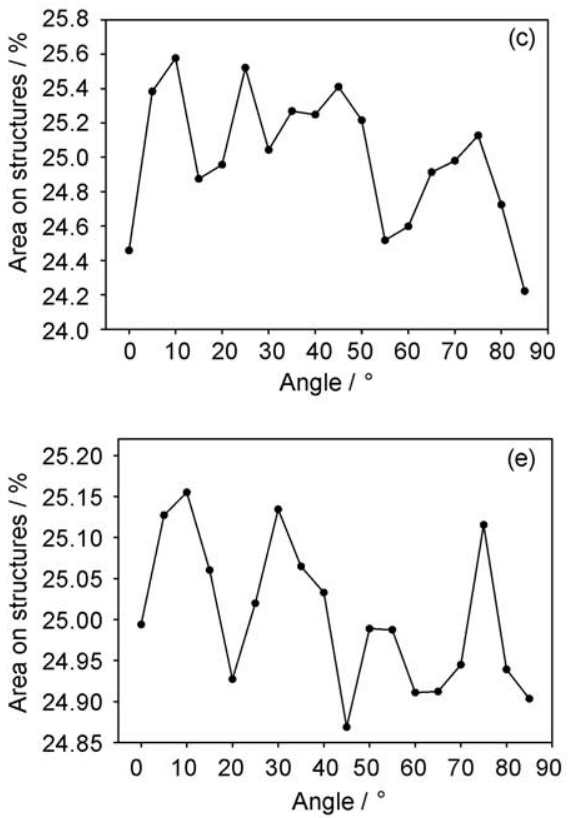

that approximate those of the structures. At $30^{\circ}$, the higher area of the cell covering the structures also suggests that the cells prefer this position. On the posts, the cells use the structures as anchorage points with which to adhere themselves to the surface. Figure 4 corroborates this finding, with the attachment points of the cells seen to adhere almost exclusively to the posts. On the holes, the cell is more likely to be attached to the area between the holes, which means that the lower angles increasingly contribute to the dataset (Figure 7). As the dimensions of the holes decrease, the $30^{\circ}$ angle rapidly becomes less dominant, suggesting that the cell is less and less affected by the surface structures.

This theoretical modeling does not, however, account for the high frequency of the cell sitting parallel to the pattern, that is, at $0^{\circ}$. At an angle of $0^{\circ}$, the cell sits either between adjacent structures or on top of them (Figure 2). Figure 9 models cells of increasing width sitting on posts. As the size of the cell increases, they sit on an increasing number of posts in adjacent rows. If the width of the cell is less than or equal to the dimensions of the structures, it has the option to sit on top of adjacent structures (A) or in the area between them $\left(\mathrm{A}^{\prime}\right)$. When the width of the cell is approximately equal to three times the width of the structure, the cell can straddle two rows of structures (C), or just one $\left(C^{\prime}\right)$. As the cell becomes wider still it is forced to sit on an increasing number of rows (D). Each of these configurations causes the area of the cell sitting on the posts to be different (Table 3).

Examination of a number of cells, aligned at $0^{\circ}$ to the pattern and with widths approaching that of the $100-\mu \mathrm{m}^{2}$ structures, shows that the cells have no preference for either configuration (A or $\mathrm{A}^{\prime}$, Figure 2). This may be counter intuitive if one considers the cell merely as a "bag of liquid", which may be expected to take the lowest energy configuration by resting on as 
Table 2. Angle the cell makes to the structures using the model described in Figure 8 a.

\begin{tabular}{ccc}
\hline $\begin{array}{c}\text { Positional reference } \\
\text { (with respect to post 0,0) }\end{array}$ & Distance $d / \mu \mathrm{m}$ & Angle $\theta{ }^{\circ}$ \\
\hline 1,0 & 10.00 & 0.00 \\
1,1 & 14.14 & 45.00 \\
2,1 & 22.36 & 30.00 \\
3,1 & 31.26 & 19.47 \\
4,1 & 41.24 & 14.48 \\
5,1 & 51.00 & 11.31 \\
6,1 & 60.84 & 9.46 \\
\hline
\end{tabular}

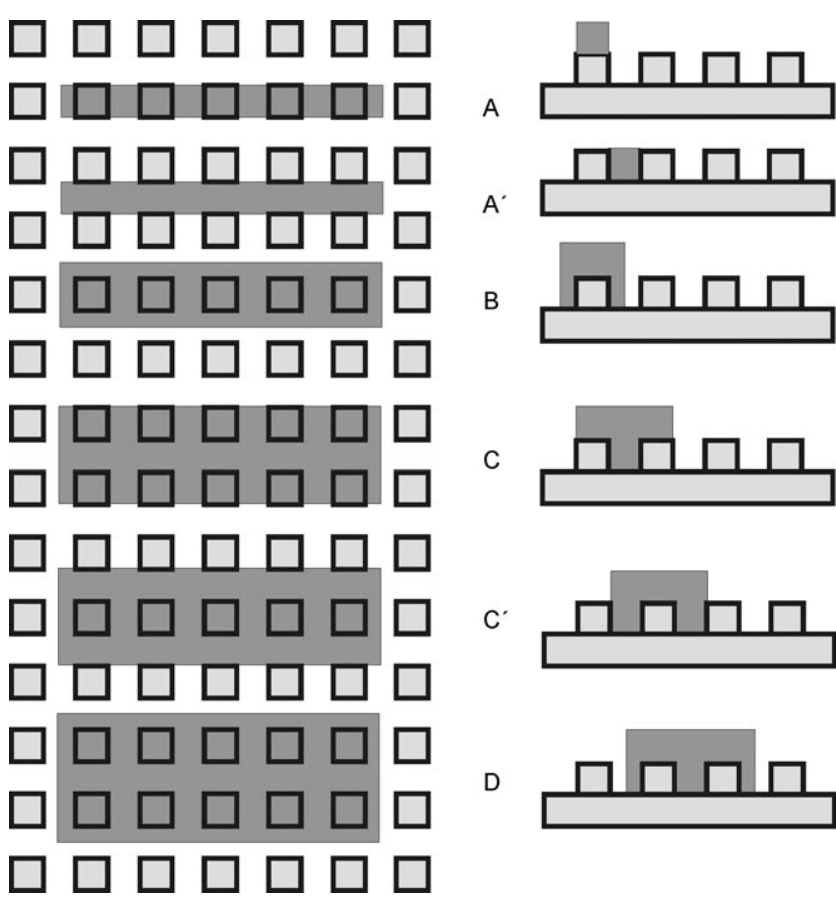

Figure 9. Diagram showing the effect of increasing cell width on the position of the cell with respect to post coverage at $0^{\circ}$. The posts (light gray squares) are covered by the cell (dark gray rectangle). As the area of the cell increases (from A to D), the cell covers an increasing number of posts.

few of the structures as possible. Instead, it again appears that some cells use the structures as attachment points. This may be to increase their contact angle with the polymer surface, producing a spherical cross section.

The results of the contact-angle measurements (Figure 5) show that the embossed, nonstructured PMMA surface is originally hydrophilic but becomes hydrophobic when patterned with microstructures. The surface also becomes increasingly hydrophobic as the dimensions of the structures are reduced. These facts may explain why the cells are thinner and more elongated, producing a more spherical cross section, than those on the nonstructured surface where the cell is forced to interact with a flat surface. Even so, this elongated configuration may not be preferable to the cells, as evidenced by the lower proliferation of the cells on the structured surface when compared to the flat surface (Figure 1).

Finally, as the dimensions of the structures decrease, the pattern should be less likely to influence the cell alignment to the pattern. However, it may be that, at these scales, the cell experiences neighboring structures as a single continuous line with which it interacts on a subcellular level, causing it to be elongated in one direction. This elongation would then be similar to the elongation seen on nanotrench structures. $^{[1,4]}$

\section{Conclusions}

MG63 cells have been shown to preferentially align at certain angles $\left(0^{\circ}, 30^{\circ}\right.$, and $\left.45^{\circ}\right)$ to the pattern of the microstructures. The cells prefer to align themselves parallel to the structures but if forced to lie on the structures tend to choose angles that minimize the distance between posts. This is thought to be due to the cell using the structures as anchorage points to attach itself to the surface. As the dimensions of the structures become much smaller than the dimensions of the cells, the cell is less influenced by the surface structures with respect to steric hindrance. At very small structural dimensions the cell is probably only influenced by the surface on subcellular scales, for example, through integrin rearrangement. ${ }^{[22]}$ Such structural surfaces clearly affect the cellular proliferation, and the alignment of the cells and their extrusions may contribute to this. Therefore, the design of structured surfaces for cell-surface interaction studies, for applications such as the design of materials for drug delivery or tissue engineering, should take care to include an examination of the surface structure as well as the surface chemistry. ${ }^{[23]}$

\section{Experimental Section}

Polymer replication: PMMA sheets $(125 \mu \mathrm{m}$ thick) were used as supplied from Goodfellow Ltd. (UK). For each experiment, the polymer was cut to the approximate size of the mold to be used

Table 3. Percentage area of theoretical cells of different widths on post structures as described in Figure 9.

\begin{tabular}{|c|c|c|c|c|c|c|}
\hline Cell & A & $A^{\prime}$ & B & C & $\mathrm{C}^{\prime}$ & $\mathrm{D}$ \\
\hline Cell length/units & 10 & 10 & 10 & 10 & 10 & 10 \\
\hline Cell width/units & 1 & 1 & 2 & 3 & 3 & 4 \\
\hline Cell area/units ${ }^{2}$ & 10 & 10 & 20 & 30 & 30 & 40 \\
\hline Area of cell on posts/units ${ }^{2}$ & 5 & 0 & 5 & 10 & 5 & 10 \\
\hline Area of cell not on posts/units ${ }^{2}$ & 5 & 10 & 15 & 20 & 25 & 30 \\
\hline Percentage area of cell on posts/\% & 50 & 0 & 25 & 33.3 & 16.7 & 33.3 \\
\hline
\end{tabular}

for the embossing. Molds with regular, ordered microstructures were used. These consisted of $9 \mathrm{~mm} \times 6.5 \mathrm{~mm}$ arrays of posts or holes with areas of 4 , 25 , and $100 \mu \mathrm{m}^{2}$ and $\sim 1 \mu \mathrm{m}$ deep/tall. The moulds were fabricated using lithographic techniques from silicon nitride $\left(\mathrm{Si}_{3} \mathrm{~N}_{4}\right)$-coated silicon. ${ }^{[24]}$ 
The $\mathrm{Si}_{3} \mathrm{~N}_{4}$ layer was used to prevent adherence problems between the mold and the polymer. However, to ensure the mold did not stick to the PMMA, a monolayer of antiadhesion fluoroalkylsilane (trichloro(tridecafluoro-octyl)silane (United Chemical Technologies, USA) was also added to the mold surface using a previously reported method. ${ }^{[25]}$

Embossing of the structures in the polymer was completed using an Obducat nanoimprinter (Obducat AB, Sweden). The mold was positioned on the base of the nanoimprinter with the structures to be embossed uppermost. The PMMA sheet was placed onto the mold and a sheet of Teflon (125 $\mu \mathrm{m}$ thick) was placed on top of the PMMA. The Teflon protects the PMMA from being patterned by the aluminum used in the nanoimprinter. ${ }^{[26]}$ The embossing then proceeded using the conditions given in Table 4. The use of a freestanding piece of PMMA (rather than using a PMMA film spun down onto a substrate, as is usual when nanoimprinting) means that the embossed PMMA can easily be used with transmission optical microscopy.

Table 4. Embossing parameters.

\begin{tabular}{lc}
\hline Embossing parameter & Value \\
\hline Embossing temperature $/{ }^{\circ} \mathrm{C}$ & 130 \\
Embossing pressure $/$ bar & 40 \\
Embossing time $/ \mathrm{s}$ & 600 \\
Release temperature $/{ }^{\circ} \mathrm{C}$ & 80 \\
\hline
\end{tabular}

Cell culturing: Osteoblast-like MG63 cells (from ATCC) were used in this work. The cells were maintained at $37{ }^{\circ} \mathrm{C}$ and $5 \%$ $\mathrm{CO}_{2}$ in complete medium (D-MEM) containing $10 \%$ fetal calf serum (FCS) and $1 \%$ each of L-glutamine, pyruvate, and streptomycin/penicillin. The structured PMMA sheets were covered with Flexiperm culture chambers (Greiner, Germany), which defines culture wells around the structured areas of PMMA. The structures were then immersed in $0.5 \mathrm{~mL}$ of the complete medium in which the MG63 cells were seeded at a density of $2 \times 10^{5}$ cells per well plate. Prior to imaging, the cells were fixed to the surface by immersion in glutaraldehyde $(2.5 \%$ solution in phosphate buffer [pH 7.3, $\left.23 \% \mathrm{NaH}_{2} \mathrm{PO}_{4} 0.2 \mathrm{M}: 77 \% \mathrm{Na}_{2} \mathrm{HPO}_{4} 0.2 \mathrm{M}\right]$ ) for one hour. Following this, the samples were washed twice with phosphate buffer at $4^{\circ} \mathrm{C}$.

Characterization: Characterization of the surfaces of the molds and the patterned PMMA was achieved using white-light interferometry (Wyko NT110; Vecco Metrology, USA) to confirm replication fidelity and repeatability. Advancing contact-angle measurements were performed using ultrapure water $(3 \mu \mathrm{L}$; Milli-Q; Millipore, USA) deposited using a contact-angle measurement system (OCA 20; Dataphysics, GmbH, Germany). Digitized optical images of the cells on the surface of the PMMA were recorded (Eclipse L150 A microscope, Nikon Instruments, Japan), and the angles the cells make to the pattern of the embossed structures was measured manually with the aid of imaging software (Corel Draw, version 11, The Corel Corporation, 2002). Statistical software (Matlab, version 6.5, The MathWorks Inc., 2002) was used to model the angles that a theoretical cell makes to the structured surfaces. Statistical analysis of the data was completed using the methods and statistical tables given in Millar and Millar. ${ }^{[21]}$

\section{Acknowledgements}

The authors thank Dr. T. Whalbrink and Dr. C. Moormann from AMO GmbH, Germany, for providing the microstructured molds, and I. Ríos-Mondragón of the Barcelona Science Park for completing the staining and imaging of the cells used in Figure 4. The authors are grateful for support for this work from the European Union 6th Framework projects "CellPROM" (NMP4-CT-2004-500039) and "Nano-2-Life" (NMP4-CT-2003500057), and from the Spanish Ministry of Science and Education (MEC) for the provision of grants through the Ramon $y$ Cajal (CAM, EM, and $A E$ ) and Juan de la Cierva (EE) grant systems. This paper and the work it concerns were generated in the context of the CellPROM project, funded by the European Community as contract No. NMP4-CT-2004-500039 and it reflects only the authors' views.

[1] A. Curtis, C. Wilkinson. Biomaterials 1997, 18, $1573-1583$.

[2] R. G. Flemming, C. J. Murphy, G. A. Abrams, S. L. Goodman, P. F. Nealey, Biomaterials 1999, 20, 573-588.

[3] A. M. P. Turner, N. Dowell, S. W. P. Turner, L. Kam, M. Isaacson, J. N. Turner, H. G. Craighead, W. Shain, J. Biomed. Mater. Res. 2000, 51, 430-441.

[4] A. S. G. Curtis, B. Casey, J. O. Gallagher, D. Pasqui, M. A. Wood, C. D. W. Wilkinson, Biophys. Chem. 2001, 94, 275-283.

[5] B. A. Dalton, X. F. Walboomers, M. Dziegielewski, M. D. M. Evans, S. Taylor, J. A. Jansen, J. G. Steele, J. Biomed. Mater. Res. 2001, 56, 195-207.

[6] C. S. Ranucci, P. V. Moghe, J. Biomed. Mater. Res. 2001, 54, 149-161.

[7] D. R. Jung, R. Kapur, T. Adams, K. A. Giuliano, M. Mrksich, H. G. Craighead, D. L. Taylor, Crit. Rev. Biotechnol. 2001, 21, $111-$ 154.

[8] H. G. Craighead, C. D. James, A. M. P. Turner, Curr. Opin. Solid State Mater. Sci. 2001, 5, 177-184.

[9] C. D. W. Wilkinson, M. Riehle, M. Wood, J. Gallagher, A. S. G. Curtis, Mater. Sci. Eng. C 2002, 19, 263-269.

[10] L. Scheideler, J. Geis-Gerstorfer, D. Kern, F. Pfeiffer, F. Rupp, H. Weber, H. Wolburg, Mater. Sci. Eng. C 2003, 23, 455-459.

[11] M. J. Dalby, N. Gadegaard, M. O. Riehle, C. D.W. Wilkinson, A. S. G. Curtis, Int. J. Biochem. Cell Biol. 2004, 36, $2005-2015$.

[12] N. Gadegaard, E. Martines, M. O. Riehle, K. Seunarine, C. D. W. Wilkinson, Microelectron. Eng. 2006, 83, 1577-1581.

[13] J. L. Charest, A. J. García, W. P. King, Biomaterials 2007, 28, 2202- 2210.

[14] D. Zahor, A. Radko, R. Vago, L. A. Gheber, Mater. Sci. Eng. C 2007, 27, 117-121.

[15] F. Johansson, P. Carlberg, N. Danielsen, L. Montelius, M. Kanje, Biomaterials 2006, 27, $1251-1258$.

[16] R. Barbucci, S. Lamponi, A. Magnani, D. Pasqui, Biomol. Eng. 2002, 19, $161-170$.

[17] J. B. Recknora, D. S. Sakaguchib, S. K. Mallapragada, Biomaterials 2006, 27, 4098-4108.

[18] J. L. Charest, M. T. Eliason, A. J. García, W. P. King, Biomaterials 2006, 27, $2487-2494$.

[19] E. K. F. Yim, R. M. Reano, S. W. Pang, A. F. Yee, C. S. Chen, K. W. Leon, Biomaterials 2005, 26, 5405-5413.

[20] Y. Zhao, X. Zhang. Sens. Actuators A 2006, 127, 216-220.

[21] J. C. Miller, N. Miller, Statistics for Analytical Chemistry, 3rd ed., Prentice Hall, New York, 1993.

[22] T. A. Springer, J-H. Wang, Adv. Protein Chem. 2004, 57, 29-63.

[23] J. L. Charest, M. T. Eliason, A. J. García, W. P. King, A. A. Talin, B. A. Simmons, J. Vac. Sci. Technol. B 2005, 23, 3011-3014. 
[24] C. A. Mills, E. Martinez, F. Bessueille, G. Villanueva, J. Bausells, J. Samitier, A. Errachid, Microelectron. Eng. 2005, 78-79, 695700.

[25] F. Bessueille, V. Dugas, J. P. Cloarec, V. Vikulov, M. Cabrera, E. Souteyrand, J. R. Martin, Biosens. Bioelectron. 2005, 21, $908-$ 916.
[26] C. A. Mills, E. Engel, E. Martinez, M. Pla-Roca, M. Funes, F. Bessueille, A. Errachid, J. A. Planell, J. Samitier in Nanotechnology at the Leading Edge (Ed.: J. P. Reece), Nova Science, New York, 2007.

Received: December 4, 2006

Revised: February 23, 2007

Published online on March 30, 2007 